\title{
SIMULATION MODEL FOR CONTAINER FLEET SIZING ON DEDICATED ROUTE
}

\author{
João Ferreira Netto \\ Rui Carlos Botter \\ Department of Naval Architeture and Oceanic Engineering \\ Polytechnic School - University of Sao Paulo \\ Av. Professor Mello Moraes, 2231 \\ São Paulo, SP 05508-030, BRAZIL
}

\begin{abstract}
Shipping companies operating with container transportation have the challenge of allocating an amount of ships with specific features (including transport capacity and speed), in a specific route, and meet the demand in a given period. For such, it is also necessary to make a container fleet available to the customers, which will be removed in the empty warehouse, loaded in the origins and sent to ports to be transported by the ships, in closed cycle, to other terminals that compose the route. This movement is based on a loading matrix of ships. This work presents a simulation model to dimension the quantity of containers required to operate with a ship fleet that attends determined route (in closed loop), and at the same time considers the loading operations of empty containers with customers, on land. It is presented a process of searching for better solutions provides results that minimize container fleet at its disposal.
\end{abstract}

\section{INTRODUCTION}

A navigation company that operates at regular market works with defined routes and a fleet of ships dedicated to those routes during, generally, a planning period of six months. To meet a demand in a determined time horizon. Besides being necessary a compatible ships' fleet, it is also necessary a containers fleet that can be loaded on board of ships, held by costumers, in transit on land or stored in ports.

As ships' cargo matrices are generally unbalanced, if considered delivery and reception, lots of ports accumulate empty containers, while others suffer from lack of them, according to Zambuzi (2010). To mitigate this "imbalance" effects, navigation companies tries to reposition empty containers, transporting them to demanding ports. An efficient reposition of empty containers between ports makes it possible to the company to have smaller containers fleets, besides prevent costs with leasing and loss of transport.

Thus, the objective is to dimension, using a simulation model and a method of search for the best solution, a container fleet at system so that clients have containers to be filled on land and sent to ports to be boarded by the navigation company, considering the reposition of empty containers between ports that compose adopted routes.

Additionally, the objective of this paper is to present a simulation model to (with the support of a tool of search for the best solution) dimension a container fleet that allows for a shipping company that operates with a fixed fleet of vessels at a dedicated route.

\section{TRANSPORT OF CONTAINERS}

Containers transport is highly used to transport goods between countries. According to UNCTAD (2010), in 2010 the world fleet of containers ships was capable to move 169 million tons of cargo. A factor that contributes to such great utility to containers is the possibility to use them in different modes without requiring many adjustments. The standardization of equipment for handling containers and development of terminals favors the transportation of those recipients. 
Containers transportation market, although being large and important, is concentrated in few companies due to the high costs involved and also operation difficulties. This restricted market makes the companies search for possibilities always offering low prices. Hence, tools that enables costs reduction, efficiency at transportation, and travel cycles' time decrement are targets of a great number of researches and analysis of big ship owners.

\section{LITERATURE REVIEW}

This work aims to size containers fleet of a navigation company, considering the possibility to reposition empty containers between ports.

A great number of studies face the problem of empties logistic. According to Di Francesco, Crainic and Zuddas (2009), the process of repositioning empty containers in a maritime system can be defined as the planning of distribution of those containers in a way that stocks, transport and handling costs are minimized while demand is attended in all ports.

Cheung and Chen (1998) defined an itinerary commonly traveled by containers during a logistic cycle. Figure 1 is an adaptation of this itinerary. In this figure, Port A represents a port that sends containers to a determined Port B, which only receives them. In real cases, ports act as containers issuers and receivers at the same time.

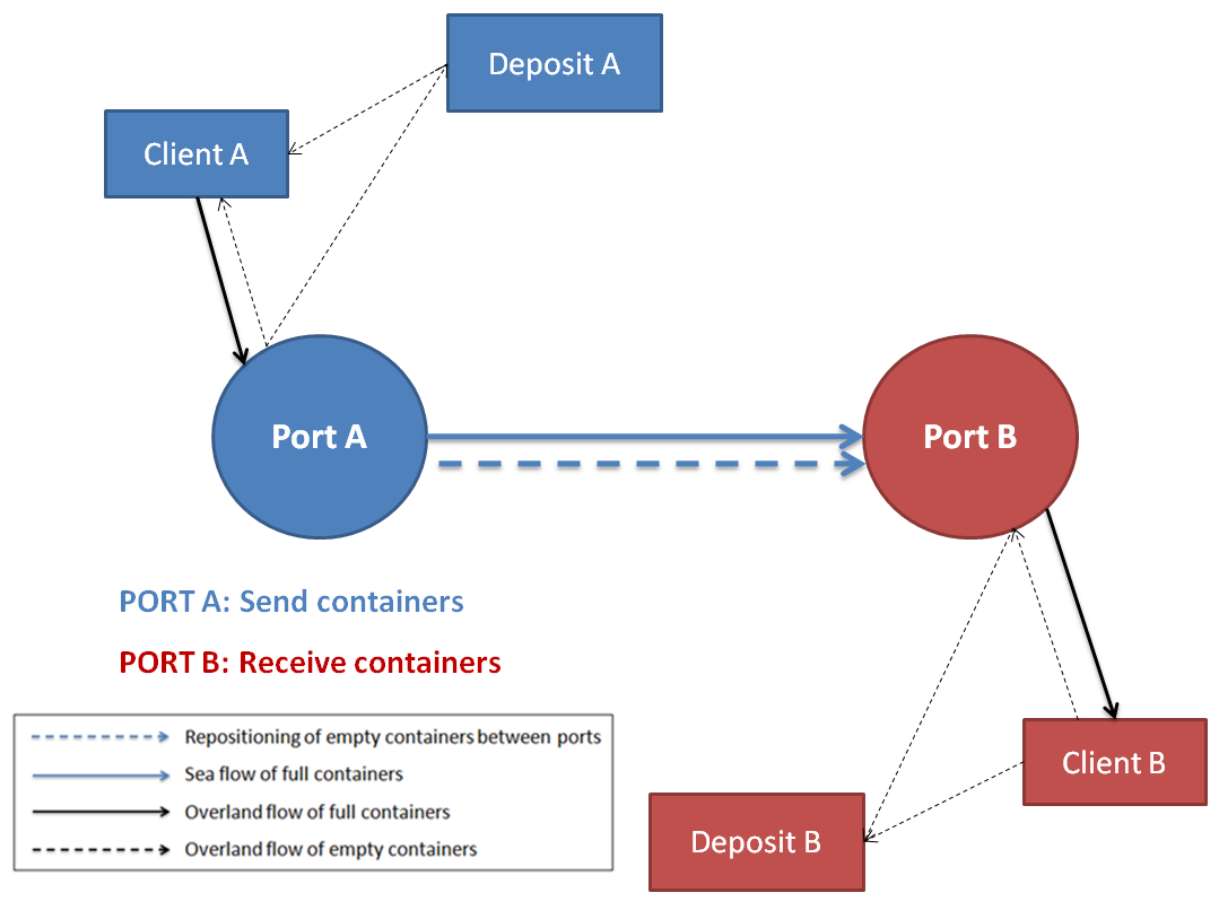

Figure 1: Graphic representation of logistic cycle of containers

Yun, Lee and Choi (2010) reported that companies usually lose time at repositioning and moving empty containers between places (ports, deposits, etc.) where they are stocked. Also, the same author cite that an efficient management in this area can increase the productivity of the company. In order to reposition empty containers on ships, those need to have space (empty slots), forcing the plan also to consider those slots in a way there is no occupation in places that should contain full containers.

According to Di Francesco, Crainic and Zuddas (2009) it is common, in big ports, to have specific areas to stocking empty containers that can be maintained during the port companies.

There are a few works found about containers fleet's sizing methodologies to a ship owner. According to Imai and Rivera (2001), to size a container fleet is a way of determining the necessary quantities to 
attend to future demands, while other fleet management problems generate actions like repositioning or leasing of empties. If a ship owner has a large proper containers fleet, it will probably need to make few empty movements and/ or containers rent, showing interdependence between strategic and operational decisions.

There are several studies about vehicles fleet sizing (trucks, trains, ships, etc) and empty containers repositioning. However, the majority of those works does not contain relevant impact in the problem of sizing of containers fleet and just a few are those that directly tackles the theme. This observation is also highlighted by Yaguiu (2006), one of the few that directly deals with containers fleet. The author affirms, among other things, that models that deal with vehicles and containers fleet sizing are different in several aspects, one of them being the randomness of transit times of containers on land.

Most of the related work use linear programming and heuristics to dimension container fleet and reposition them, when empty. Based on this assumption, it was decided to use the simulation of discrete events as the tool for addressing, and solve the proposed problem. The model description, as well as the results, will be presented as follows.

\section{SIMULATION MODEL FOR HANDLING OF CONTAINERS (FULL OR EMPTY) ON DEDICATED ROUTE AND FIXED SHIP FLEET}

Discrete event simulation was adopted as a technique of resolution of the problem presented at this paper, presenting great advantages when compared with other known techniques, as the possibility of fast evaluation of proposed strategies, usage of low robust data, higher facility in detailing a complex system, the comprehension of which variables are really influent and orientate obtained results, identification of systems bottleneck and true representation of events, interconnecting subsystems and enabling the complete evaluation of interdependence among them. Moreover, the problem has a stochastic nature and discrete event simulation is a tool indicated for this kind of situation.

A simulation model was created to simulate a maritime containers transportation route between ports in a closed cycle with determined ships' fleet. For this simulation some assumptions were considered, such as: (1) availability of berths in each terminal included at the simulated scenario, and (2) the possibility of system configuration, varying the number of visited ports, size of fleet and cargo matrices to be attended.

The simulation model comprehends two interconnected sub models: (1) ships circulation sub model, and (2) on land containers circulation sub model (both presented in this section). The first sub model that composes containers transport simulation in a closed cycle represents ships' travels and port operations according to pre-defined routes and cargo matrices. Cargo matrices of ships were established in a planning phase to ensure that the owner of the ship have profitability if attending, at least, those cargos represented in those matrices.

After the ships of the considered fleet are created, model attributes specific characteristics of each one, as number of travels and sequence of ports that will be visited in routes considered for them. Ships are, then, positioned at ports defined as initial for each ship-travel. Among the operations that the model does each time a port is allocated to a ship, it is considered boarded containers unloading at that port and loading (when there is enough stock of full containers at the port), and also the decision about repositioning or not the empty containers. Quantities are defined based on informed values of cargo matrices. Further, it is subtracted from the unloaded quantity the number of containers removed from ports, having then the total of containers that must remain on land after the ship finishes its operation. This is the total that determines, for the model, if the port is the offering or demanding one for empty containers. In ports which the total is positive, ports are offering. Otherwise, if a port has negative total, it is a demanding one.

After ports are divided according to their visit sequences, they must be divided in groups that start with offering ports. In those groups, the maximum quantity that will remain from a cycle at offering ports is removed, in other words, a quantity which is equal to positive total of that port is removed. It is calculated, then, the percentage from this total that needs to be unloaded at ports that succeed this offering one until the ship arrives at other offering port. 
For instance, if 428 empty containers are removed at an offering port and next port is demanding 376 containers, it is known that at that port will be unloaded $87,9 \%$ of empties on board, and 52 empty containers will remain at the ship. If the next visited port is a demanding, percentage of empties that remained on board of the ship that shall be unloaded will be calculated, otherwise, new empties will be loaded, accumulating the quantity of on board containers. Exemplifying, if the following port has a positive total of 818 containers (offering port, hence), there will be 870 empty containers on board of ship to be unloaded at ports. It is presented this example because

Figure 2 explains this mechanism of containers repositioning, showing percentages of on board containers that will be unloaded in each demanding port.

\begin{tabular}{|c|c|c|c|c|c|}
\hline \multicolumn{3}{|c|}{ Port Sequence: 1 - 2 - 3 - 5 - $6-4$} & $\begin{array}{l}\text { Maximum of containers } \\
\text { quantity to be loaded }\end{array}$ & $\begin{array}{l}\text { Percentage of total } \\
\text { capacity to be loaded }\end{array}$ & \multirow[t]{2}{*}{$\begin{array}{l}\text { capacity to be } \\
\text { unloaded }\end{array}$} \\
\hline \multicolumn{3}{|c|}{ Balance } & & & \\
\hline Port 1 & 428 & offering & 428 & $100.0 \%$ & $0.0 \%$ \\
\hline Port 2 & -376 & demanding & - & $0.0 \%$ & $87.9 \%$ \\
\hline Port 3 & 818 & offering & 870 & $100.0 \%$ & $0.0 \%$ \\
\hline Port 4 & -39 & demanding & - & $0.0 \%$ & $100.0 \%$ \\
\hline Port 5 & -362 & demanding & - & $0.0 \%$ & $41.6 \%$ \\
\hline Port 6 & -469 & demanding & - & $0.0 \%$ & $92.3 \%$ \\
\hline
\end{tabular}

Figure 2: Representation of empty containers reposition mechanism

At Figure 2's example, the presented scenario has the visited ports sequence of $1-2-3-5-6-4$, in which only ports 1 and 3 are offering while the others are demanding. It is important to note after visiting port 1 and removing from it 428 empty containers, the necessary repositioning for port 2 is $87,9 \%$ of on board total, and containers loaded at port 3 accumulate, being unloaded at ports 5, 6 and 4 .

Figure 3 presents a schematic representation of containers quantities that are loaded and unloaded at ports in each ship's travel.

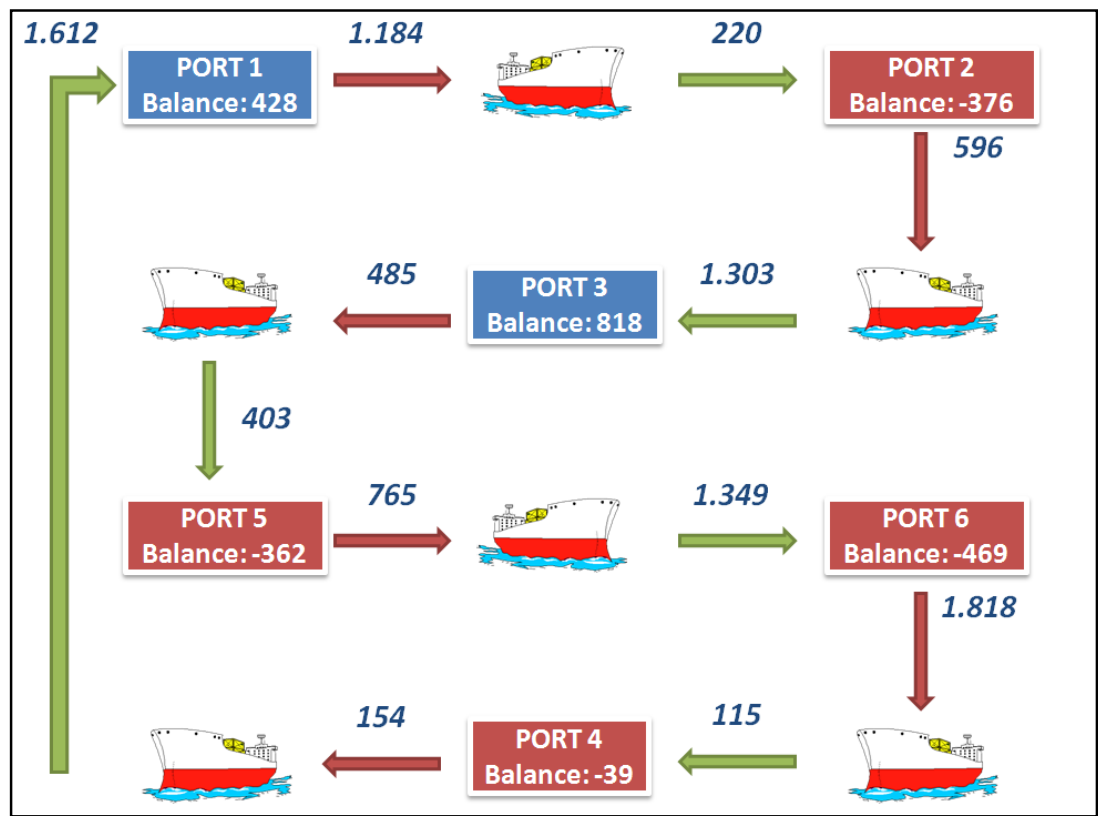

Figure 3: Representation of containers quantity loaded and unloaded at each port

Besides the already presented ships circulation sub model, it was built a sub model to represent circulation of containers on land. This sub model handles the operations with empty containers that are at ports 
and are sent to be filled at clients, returning full to ports before being loaded and transported, and containers that are unloaded full at ports and are sent to recipients, that will empty and return them to port stockings located in regions next to ports considered at the simulation.

In this sub model there are two different logics: one that draws (from a statistic distribution that considerate data from cargo matrix) diary demand of empty containers of a considered port and that will result at generating containers to be sent full to terminals to be loaded at ships, and the logic that should deal with containers that come full to ports to clients on land and are empty and returned to stocking at ports.

For validating the simulation model, a complete log of ships at the end of each replication was created, through which it was possible to detail all inventory updates that occur in ports along the trips (for all ships) and verify the number of repositioned containers. Thus, it was found that the matrices cargoes provided by the shipping company were respected by the model and the loading sequences have worked correctly.

It should be highlighted that this model can be used for any fleet, route or matrix of cargoes, since the input data is generic and all information could be filled into a spreadsheet in Excel, read by the simulation model. A specific case is presented because information (data) were the only provided by one shipping company (it was changed for confidentiality reasons, but keeping its magnitude). Such information is difficult to obtain and frequently are only obtainable through formal requests often denied by shipping companies.

\subsection{Method for search of the best solution}

As a support to the simulation model built, we used a tool for search of solutions next to optimal to determine the containers fleet that must be used by navigation company (fleet sizing). To search for the best solution and responses of system, the tool OptQuest of ARENA ${ }^{\circledR}$ was used. Search process considered initial stocks at ports (full "in", full "out" and empty) as decision variables.

OptQuest is a mechanism to search for the best solution and is based in scatter search techniques associated to tabu search procedure to obtain solutions to defined problems in complex tools (Laguna, 1997). In other words, OptQuest looks for decision variables that are next to the optimal solution of the problem using evaluation of obtained responses to the object functions, based in heuristics.

This process of search for best solution contributed, in this study, to find a smallest initial containers stock (fleet), minimizing the loss of transportation. Being the problem objective function the addition between loss of transportation and quantity of initial containers stock (fleet), the problem of searching for the best solution must solve the following expression:

$$
\min O F=\sum_{j}^{n}\left(E I_{j}\right)+k \cdot \sum_{j}^{n} P_{j}, j=1,2,3, \ldots, n
$$

OF: Objective function

$\mathrm{EI}_{\mathrm{j}}$ : Initial stock at port $\mathrm{j}$

$P_{\mathrm{j}}$ : Loss of transportation at port $\mathrm{j}$

$\mathrm{k}$ : Multiplicative factor for loss of transportation

The factor $\mathrm{k}$ can be replaced by values considered high to force, in the resolution of the problem, so that the objective function be minimized, loss of transportation should come near zero.

\section{RESULTS}

\subsection{Initial Processing from Sufficient Stock to attend the Demand Integrally}

This first simulated scenario is the starting point for the simulation of scenarios of search for containers fleet sizing and future sensitivity analysis in function of important parameters. It was constructed from in- 
put data and premise given by a Brazilian navigation company, representing a regular operation of all system that includes six ports of determined route and four ships.

Visits of ports' sequence are the same for all four fleet's ships:

- Visits sequences: port 1 - port 2 - port 3 - port 5 - port 6 - port 4.

Being ships' speed equal to $15 \mathrm{knots}(27.8 \mathrm{~km} / \mathrm{h})$ (its capacity equal to $3.000 \mathrm{TEU}$ 's), through distance matrices between ports, travel durations between them are obtained. Table 1 shows distances, in kilometers, between 6 ports considered at ships' fleet.

Table 1: Matrix of distance between considered ports

\begin{tabular}{|l|l|l|l|l|l|l|}
\cline { 2 - 7 } \multicolumn{1}{c|}{} & PORT 1 & PORT 2 & PORT 3 & PORT 4 & PORT 5 & PORT 6 \\
\hline PORT 1 & 0 & $83.4 \mathrm{~km}$ & $695.7 \mathrm{~km}$ & $921.7 \mathrm{~km}$ & $1083.7 \mathrm{~km}$ & $1990.8 \mathrm{~km}$ \\
\hline PORT 2 & $83.4 \mathrm{~km}$ & 0 & $612.3 \mathrm{~km}$ & $838.3 \mathrm{~km}$ & $1000.3 \mathrm{~km}$ & $1907.4 \mathrm{~km}$ \\
\hline PORT 3 & $695.7 \mathrm{~km}$ & $612.3 \mathrm{~km}$ & 0 & $226.0 \mathrm{~km}$ & $388.0 \mathrm{~km}$ & $1457.1 \mathrm{~km}$ \\
\hline PORT 4 & $921.7 \mathrm{~km}$ & $838.3 \mathrm{~km}$ & $226.0 \mathrm{~km}$ & 0 & $162.0 \mathrm{~km}$ & $1069.1 \mathrm{~km}$ \\
\hline PORT 5 & $1083.7 \mathrm{~km}$ & $1000.3 \mathrm{~km}$ & $388.0 \mathrm{~km}$ & $162.0 \mathrm{~km}$ & 0 & $907.1 \mathrm{~km}$ \\
\hline PORT 6 & $1990.8 \mathrm{~km}$ & $1907.4 \mathrm{~km}$ & $1457.1 \mathrm{~km}$ & $1069.1 \mathrm{~km}$ & $907.1 \mathrm{~km}$ & 0 \\
\hline
\end{tabular}

The average duration of containers operation is considered in each port, considering berthing and unberthing of vessels. For this values a triangular distribution is used (with $30 \%$ variation in relation to the mode, in other words, the smallest value is $30 \%$ smaller than the mode while the biggest, $30 \%$ bigger than the same mode) that, according to the company that provided data, adheres to real data. The average retention time of containers on land used was 15 days, also considering a triangular distribution with $30 \%$ variation, according to the informed by navigation company.

For this initial scenario, it was used a containers initial stock (containers fleet) big enough to makes the system works without loss of transportation due to lack of containers. This initial containers stock (total of full "in", "out" and empty containers stock in all ports of considered route) was determined from initial tests using the model. Full "in" containers stock represents containers that arrive from ships to ports, while full "out" containers refers to full containers that arrive at ports to be loaded at ships and transported.

Based on cargo matrix, diary quantity of empty containers that clients need was calibrated. The quantity of containers at initial stocks used for simulation this initial scenario is presented on Table 2 .

Table 2: Initial containers stock at initial scenario

\begin{tabular}{|l|r|}
\hline Full "in" containers initial stock at PORTS & 5,150 \\
\hline Full "out" containers initial stock at PORTS & 34,200 \\
\hline Empty containers initial stocks at PORTS & 36,900 \\
\hline TOTAL CONTAINERS INITIAL STOCK & $\mathbf{7 6 , 2 5 0}$ \\
\hline
\end{tabular}

In this simulation it was obtained the average cycle time of ships that, divided by the size of the fleet (4 ships), gave the average period that ships must be inserted at the beginning of simulation processing. It should be noted that in this simulation beginning, each ship is empty and starts cycle by the first port of sequence. Being the average cycle of 365 hours and fleet composed by 4 ships, interval is equal to 91 hours. 


\subsection{Search of the Best Solution to the Problem: Sizing of Containers Fleet Minimizing Loss of Transportation by Multiplication of the Term in the Objective Function}

As previously said, it is possible to prioritize the minimization of stock or loss. Thus, we search the adequate containers fleet. Initially, it was done an experiment of 1,000 simulations with 5 replications each to determine initial stock of containers that minimized objective function without pondering any factor that composed it (total between transportation loss and initial stock). Used computer is equipped with Intel ${ }^{\circledR}$ i7 processor, with $8 \mathrm{MB}$ of RAM memory and total duration of experiment (1,000 simulations) was 550 minutes.

After this simulation, obtained results with OptQuest showed an objective function of 66,279, representing a total containers stock of 64,972 and loss of transportation of 1,317 clients' containers. Ideal is, however, to look for the smallest containers fleet with zero loss of transportation. In other scenarios, loss of transportation was multiplied, at objective function, to $100,1,000,10,000$ and 1,000,000. Hence, when searching an objective function minimization, OptQuest should force the search for a zero transportation loss and minimize initial stocks to determine the one that attend to route necessities. Obtained values at this tests are presented at Table 3.

Table 3: Containers stocks obtained in experiments with multiplier factor of loss at objective function

\begin{tabular}{|l|r|r|r|r|r|}
\hline Loss multiplication factor & $\mathbf{1}$ & $\mathbf{1 0 0}$ & $\mathbf{1 , 0 0 0}$ & $\mathbf{1 0 , 0 0 0}$ & $\mathbf{1 , 0 0 0 , 0 0 0}$ \\
\hline Empty initial stock & 29,765 & 28,930 & 5,073 & 5,073 & 5,073 \\
\hline Full out initial stock & 30,429 & 35,444 & 35,829 & 35,829 & 35,829 \\
\hline Full in initial stock & 4,778 & 5,080 & 29,034 & 29,034 & 29,034 \\
\hline Initial total stock & $\mathbf{6 4 , 9 7 2}$ & $\mathbf{6 9 , 4 5 4}$ & $\mathbf{6 9 , 9 3 6}$ & $\mathbf{6 9 , 9 3 6}$ & $\mathbf{6 9 , 9 3 6}$ \\
\hline Total loss & $\mathbf{1 , 3 1 7}$ & $\mathbf{2 2}$ & - & - & - \\
\hline Objective function & $\mathbf{6 6 , 2 7 9}$ & $\mathbf{6 9 , 6 7 4}$ & $\mathbf{6 9 , 9 3 6}$ & $\mathbf{6 9 , 9 3 6}$ & $\mathbf{6 9 , 9 3 6}$ \\
\hline
\end{tabular}

When minimizing objective function with a multiplication factor of 100 times at transportation loss, a stock of 69,936 containers was obtained at the system without loss of transportation, a better containers fleet than the one considered at initial processing, with total demand attending. From now on, such scenario will be named base scenario.

\subsection{Sensitivity Analysis: Changes in Retention Times of Containers (Full and Empty) on Land}

A proposed sensitivity analysis considers the variation in containers retention time on land and at ports. The modeling considers that, both full and empty containers must be retained for some time before being transported from ports to clients and vice versa. In this retention period, the time used for transportation, handling, cleaning are included, as well as time used at all operations since the container leaves the port until the moment when it returns to the terminal, empty or full.

Retention time was changed to verify system's behavior in function of this parameter. The consulted ship owner informed that this time can be considered of 15 days, an average, if adopting a triangular distribution with $30 \%$ variation. It can be understood that a higher retention time creates a need for a larger containers fleet to compensate waiting time on ports, while a smaller retention time makes the containers necessity decrease. To verify the impact of this random variable at system, scenarios were simulated with retention average time on land equal to 10,17 and 20 days.

For the situation of smaller retention time, loss of transportation was zero, because we know that scenario base's containers fleet is enough for the system to attend the demand with a greater retention time. However, if average retention time is equal to 20 days, transportation loss is of 38,559 containers. Said that, we used OptQuest at 100 experiments to determine the minimum containers fleet that a company 
must have to attend the demand with a higher retention time, without having loss of transportation. Initial obtained stocks are presented at Table 4.

Table 4: Initial containers stock of sceneries for on land containers retention effect analysis

\begin{tabular}{|l|r|r|r|r|}
\hline $\begin{array}{l}\text { Average retention of containers } \\
\text { time on land }\end{array}$ & \multicolumn{1}{|c|}{$\begin{array}{c}\text { (Base Scenario) } \\
\text { 15 days }\end{array}$} & 17 days & \multicolumn{1}{c|}{$\mathbf{2 0}$ days } \\
\hline Empty initial stock & 26,794 & 29,034 & 39,023 & 61,254 \\
\hline Full out initial stock & 30,366 & 35,829 & 42,968 & 55,140 \\
\hline Full in initial stock & 4,613 & 5,073 & 24,322 & 44,844 \\
\hline Total & $\mathbf{6 1 , 7 7 3}$ & $\mathbf{6 9 , 9 3 6}$ & $\mathbf{1 0 6 , 3 1 3}$ & $\mathbf{1 6 1 , 2 3 8}$ \\
\hline
\end{tabular}

It can be observed at Table 4 that the containers fleet necessary to avoid loss if average retention time is 20 days is bigger than the double of base scenario containers fleet, showing great impact that this retention time causes at system once containers are retained during a longer period of time. Figure 4 shows, also, those results.

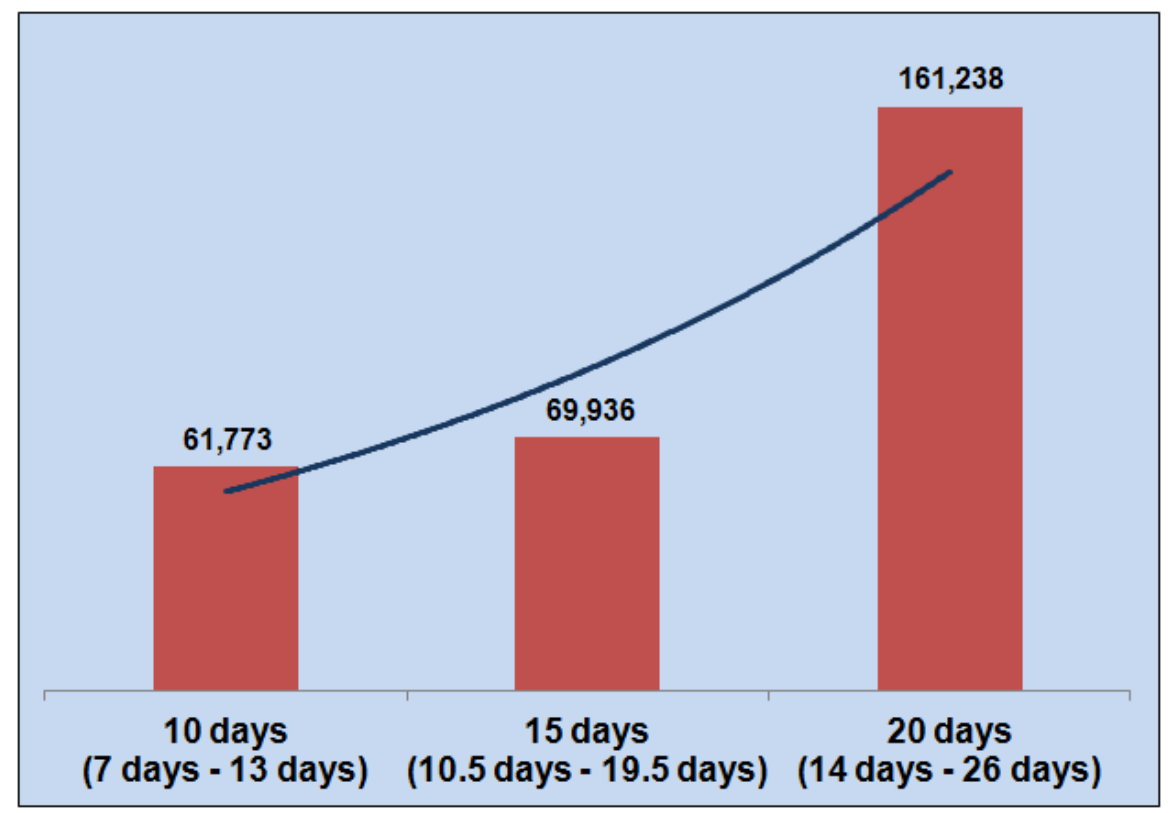

Figure 4: Initial stock of containers for analysis of land retention

We can see that the curve has a certain exponential behavior, showing the strong impact which the retention time on land causes to the system.

\section{CONCLUSIONS}

It can be concluded that discrete events simulation is a tool capable to treat the problem of containers fleet dimensioning a ships' fleet navigation to meet the demand in a closed cycle efficiently and to obtain satisfactory results.

Thus, with simulation model and the help of search tool OptQuest, processing time of proposed scenarios was considered appropriate, transforming this simulator into a capable tool to be used at planning of big navigation companies, as well as at generation of new scenarios due to changes happened at initial used premise. 
Initial containers stocks at ports (containers fleet) were obtained in all specified scenarios and simulation model was validated.

Presented results showed coherency of this sizing in view of sensitivity analysis that were realized.

It can be noted that the most important parameter is retention time of containers on land, which elevates the size of necessary fleet more than the alteration at ships' speed, when both parameters are considered.

\section{DISCUSSION}

The main contribution of this work is the use of simulation coupled with the search for the best solution to a problem very recurrent in the maritime transport sector. Among an extensive literature review, there are no examples of the use of this methodology for the sizing fleet of containers from a shipping company.

Moreover, the study of techniques that combine the simulation with operations research techniques that allow to solve optimization problems and seek improvements of various logistics systems is growing, because it is something that combines all the advantages of dealing with a complex problem (and with a stochastic character) with discrete event simulation it was raised the possibility of obtaining results near to the optimal solutions for this problem.

\section{REFERENCES}

Cheung, R. K. and C. Y. Chen. 1998. “A Two-Stage Stochastic Network Model and Solution Methods for the Dynamic Empty Container Allocation Problem.” Transportation Science 32(2), 142-162.

Francesco, M., T. G. Crainic and P. Zuddas. 2009. "The Effect of Multi-Scenario Policies on Empty Container Repositioning." Transportation Research part E 45, 758-770.

Imai, A., F. Rivera. 2010. "Strategic fleet size planning for maritime refrigerated containers." Maritime Policy \& Management 28:4,361-374.

Laguna, M. 1997. "Optimization of Complex Systems with OptQuest." Graduate School of Business Administration.

UNCTAD. 2010. Review of Maritime Transport. United Nations Conference on Trade and Development. New York and Geneva. ONU.

Yaguiu, K. 2006. "Modelo para o dimensionamento de uma frota de contêineres para uma empresa de navegação." M.Sc. dissertation, Department of Naval Architecture and Oceanic Engineering, Polytechnic School of University of Sao Paulo, Sao Paulo, Sao Paulo, Brazil. http:/www.teses.usp.br/teses/disponiveis/3/3135/tde-11122006-151046/en.php [Accessed September $8,2012]$.

Yun, W. Y., M. L. Lee and Y. S. Choi. 2010. "Optimal inventory control of empty containers in inland transportation system." International Journal of Production Economics, doi:10.1016/j.ijpe.2010.06.016.

Zambuzi, N. C. 2010. "Modelo de decisão para o planejamento da movimentação de contêineres vazios." M.Sc. dissertation, Department of Logistics Systems, Polytechnic School of University of Sao Paulo, Sao Paulo, Sao Paulo, Brazil. http://www.teses.usp.br/teses/disponiveis/3/3148/tde-16082010153458/en.php [Accessed July 1, 2013].

\section{AUTHOR BIOGRAPHIES}

JOÃO FERREIRA NETTO is a researcher from CILIP (Innovation Center for Logistics and Ports Infrastructure) situated in School of Engineering at University of Sao Paulo. He graduated in 2012 with an M.S. in Logistics Engineering at Polytechnic School of University of Sao Paulo. He developed and managed over 20 projects as a consultant using Arena in humanitarian logistics, health care, supply chain, mining, steel company and port terminals and systems. He also researches modeling techniques of stochastic systems: simulation, queuing theory and Markov decision process. His email is joaofnetto@usp.br. 
RUI CARLOS BOTTER is a Full Professor at the Polytechnic School (College of Engineering) at University of São Paulo, Brazil. He holds a PhD and Master Degree in Naval Architecture and Oceanic Engineering at the Polytechnic School (College of Engineering). He has more than 25 years that experience in logistics and ports development. His e-mail is rcbotter@usp.br. 